\title{
Computation of Flow Field over MUSES-C Space Reentry Capsules in Supersonic Speeds
}

\author{
R. C. Mehta*
}

Department of Aeronautical Engineering Noorul Islam Centre for Higher Education Kumaracoil 629180, India

The structure of the flow of a reentry capsule MUSES-C and the resulting base pressure has been numerically investigated. A computational fluid dynamics CFD analysis of the flow in base region of a planetary reentry capsule is studied. The present paper uses CFD to investigate the steady state perfect fluid dynamics of a reentry space capsule at zero angle of incidence with emphasis on the flow physics of the capsule. A CFD based investigation of the complex flowfield over the MUSES-C is carried out employing finite volume code. The present paper investigates phenomena associated with the flow in the fore body and as well as base region of the MUSES-C. The present paper is aimed to analyze numerical solutions of viscous flow past the reentry capsule and focusing on the characteristics of the near wake flow detachment, free shear layer evolution, lip shock formation, recirculation region, and upstream influence. The approaching boundary layer separates at the corner and the free-shear layer is formed in the wake region. A low pressure is formed in the base region of the capsule which is characterized by a low-speed recirculation zone

Keywords: Flow Field MUSES-C Reentry Capsules.

Copyright $\odot 2020$ The Author(s): This is an open-access article distributed under the terms of the Creative Commons Attribution 4.0 International License (CC BY-NC 4.0) which permits unrestricted use, distribution, and reproduction in any medium for non-commercial use provided the original author and source are credited.

\section{Nomenclature}

$\begin{array}{ll}\mathrm{A} & =\text { maximum base area } \\ \mathrm{C}_{\mathrm{d}} & =\text { discharge coefficient } \\ \mathrm{C}_{\mathrm{D}} & =\text { aerodynamic drag coefficient } \\ \mathrm{Cp} & =\text { pressure coefficient } \\ \mathrm{c} & =\text { speed of sound } \\ \mathrm{D} & =\text { maximum diameter } \\ \mathrm{E} & =\text { total specific energy } \\ \mathrm{e} & =\text { internal specific energy } \\ \mathrm{M} & =\text { Mach number } \\ \mathrm{p} & =\text { pressure } \\ \mathrm{q}_{\mathrm{j}} & =\text { heat flux component } \\ \mathrm{q} & =\text { dynamic pressure } \\ \mathrm{Re} & =\text { Reynolds number } \\ \mathrm{t} & =\text { time } \\ \mathrm{T} & =\text { temperature } \\ \mathrm{u}, \mathrm{v} & =\text { velocity components } \\ \mathrm{x}, \mathrm{r} & =\text { polar coordinates } \\ \mathrm{V}_{\mathrm{S}} & =\text { displaced volume } \\ \mathrm{V}_{\infty} & =\text { velocity of space capsule } \\ \gamma & =\text { ratio of specific heats } \\ \delta & =\text { Kronecker delta } \\ \theta & =\text { non-dimensional parameter } \\ \mu & =\text { molecular viscosity } \\ \rho & =\text { density } \\ \tau & =\text { viscous stress tensor } \\ & \end{array}$

$$
\begin{array}{ll}
\text { Subscripts } & \\
\mathrm{B} & =\text { base } \\
\mathrm{F} & =\text { front } \\
\mathrm{i}, \mathrm{j} & =\text { indicial notations } \\
\mathrm{S} & =\text { swept } \\
\infty & =\text { freestream }
\end{array}
$$

\section{INTRODUCTION}

With rapid advancements in computer technology and numerical algorithms computer-aided technology of high-speed reentry capsules has started significant role in aerodynamic design and analysis. The fluid dynamics problem associated with high speed reentry capsules needs an in-depth aerodynamic investigation. Thus, a strong link between CFD scientist and practical designer is well established. Several space reentry configurations such as Apollo, Soyuz, MUSESC Mu-Science-Engineering Satellite-C, EXPRESS EXPeriment and Recovery of Space System, COMET COMmercial Experiment Transporter, AFE Aeroassist Flight Experiment, ARD Atmospheric Reentry Demonstrator, Beagle 2 Mars Pathfinder, Viking and Bi-cone, Orbital Reentry EXperiments OREX, Delft Aerospace Recovery Test DART, Space Recovery Experiment SRE, Orion Crew Module OCM, Stardust Sample Return Capsule have been studied numerically 
and experimentally. The presence of a sting support disturbs the structure of the shear layer influence at the vicinity of wake neck region. During experimental study, data without rear support is not possible. The near wake structure, the interaction of converging shear layers at the wake neck largely develops the base pressure. The wake neck is characterized by a strong interaction between the interior viscous flow and the external inviscid supersonic flow. Cassanto [1] has described the physical picture of the base flow. Tanner [2] has reviewed the steady base pressure of various geometrical configurations as a function of freestream Mach numbers. Further theoretical and experimental results concerning the base pressure in supersonic base has been analyzed by Tanner [3] considering the ratio of height of the shear layer affected wake shock to the reattaching shear layer thickness. A comprehensive review of experimental base pressure and base heating data related to low supersonic to hypersonic flight vehicle is presented by Lamb and Oberkamf [4]. Particular attention is made to free-flight data as well as wind-tunnel data for models without rear sting support. Base drag represents the loss in recovery of pressure over the base of body. Laminar base-flow region has been investigated by Baum, King, and Denison [5]. The influence of nose bluntness and Mach and Reynolds numbers has been studied in conjunction with the effects on the structure of the recirculation wake by Grasso and Pettinelli [6] at laminar near-wake hypersonic flows. Berger [7] has published book on the laminar wakes in year 1971. Numerical simulation of base pressure and base drag coefficients of various space reentry capsules at freestream Mach number range of $1.2-6.0$ has been carried out recently by Mehta [8]. It is observed in the numerical simulation studies that the wave drag or fore-body pressure drag is the axial component of the integral of surface pressure over the fore-body area and tabulated for different space reentry capsules. Aerodynamics of Mars pathfinder probe at the Martian atmosphere has been numerically investigated employing inviscid solution code (HALIS) by Gnoff et al. [9].

The present paper investigates flowfield characteristics past MUSES-C (Mu-ScienceEngineering Satellite-C or HAYABUSA) which is a discovery class mission is launched on 9 May 2003 and return Earth (Australia) on 13 June 2010 [10]. There exists a considerable body of Japanese research papers [11 -15] describing the theoretical, numerical and experimental investigations of flowfield over the MUSES-C space reentry capsule.

Figure 1 illustrates the wake flow patterns at zero angle of attack which is based on several numerical simulations space reentry capsules [8]. The forebody region is characterized by a strong bow shock that decelerates the supersonic flow and causes high values of pressure, density and temperature in the shock layer. Base pressure is a complex phenomenon and is a function of many variables such as fore-body/after body configuration and trajectory parameters and in the wake a lip shock and further downstream by re-compression shock. At the end of recirculating flow past the neck, the shear layer develops in the wake trail. A complex inviscid wave structure often includes a lip shock wave (associated with the corner expansion) and wake trail (adjacent to the shear layer confluence). A free shear layer is characterized by nearly zero velocity derivatives at the edge of the layer. The corner expansion process is a Prandtl-Meyer expansion fan accompanying with the presence of the approaching boundary layer.

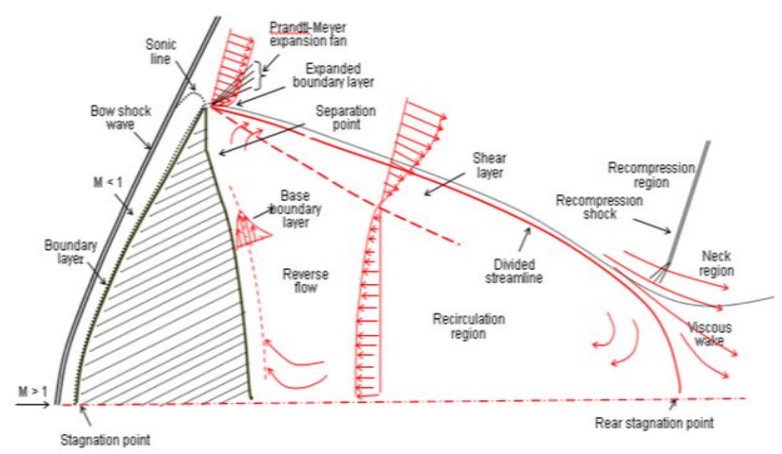

Fig-1: Schematic sketch of flow field over space reentry capsule

The shear layer or mixing region is unaffected by the reverse flow, so that it can be calculated as a free shear layer by the usual error function profiles for compressible non-isentropic flow. However, the experimental data has shown that the reverse flow has a significant effect on the shear layer velocity profile below the dividing streamline.

The purpose of the numerical analysis is to compare the base pressure drag coefficient of the MUSES-C with CFD results and with the available experimental data for $\mathrm{M}_{\infty}=1.2-3.0$. A low pressure is formed immediately downstream of the base which is characterized by a low speed circulating flow region. The wake region will occupied by fluid through the boundary layer and the expansion fan at the shoulder.

\section{Governing Equations and Numerical Algorithm}

To analysis and investigate the flow characteristics over reentry capsules at high speed, the unsteady, laminar compressible two-dimensional axisymmetric Navier-Stokes equations are written in the following conservation form:

$$
\begin{aligned}
& \frac{\partial \rho}{\partial t}+\frac{\partial}{\partial x_{j}}\left(\rho u_{j}\right)=0 \\
& \frac{\partial \rho u_{i}}{\partial t}+\frac{\partial}{\partial x_{j}}\left(\rho u_{i} u_{j}+\delta_{i j} p-\tau_{i j}\right)=0
\end{aligned}
$$




$$
\frac{\partial \rho E}{\partial t}+\frac{\partial}{\partial x_{j}}\left[\rho u_{j}\left(E+\frac{p}{\rho}\right)-u_{i} \tau_{i j}+q_{j}\right]=0
$$

The temperature is related to pressure and density by the perfect gas equation of state as

$$
p=\rho(\gamma-1)\left[e-\frac{1}{2} u_{i} u_{j}\right]
$$

The coefficient of molecular viscosity is calculated according to Sutherland's law. The flow over the space module is considered to be laminar which is consistent with the earlier numerical simulations $[5,6$, 8].

\section{Numerical algorithm}

To simplify the spatial discretization, the governing fluid dynamics Eq. (1) can be written in the integral form over a finite computational domain with the boundary of the computational region. The inviscid fluxes are computed at the centre of the cell resulting in flux balance. The summation is carried out over the four edges of the cell. The contour integration around the boundary of the cell is performed in anticlockwise sense in order to keep flux vectors normal to boundary of the cell. The computational domain is having a finite number of non-overlapping quadrilateral cells. The conservation variables within the computational cell are represented by their average values at the cell centre. The numerical approximation of space derivatives needed for evaluating the viscous contribution is obtained from second order dicretization formulas by means of the Gaussian theorem.

The derivatives of primitive variables in the viscous flux are evaluated by using the method of lines. A system of ordinary differential equations in time is obtained after integrating over a computational cell. In the cell-centred spatial discretization scheme is nondissipative, therefore, artificial dissipation terms [17] are added by blending of second- and fourth-order differences of the vector conserved variables. The blend of second and fourth differences provides third order back ground dissipation in smooth region of the flow and first-order dissipation in shock waves.

The spatial discretization described above reduces the integral equations to semi-discrete ordinary differential equations. The system of ordinary differential equations is solved using multi-stage Runge-Kutta time-stepping technique of Jameson et al. [17]. The numerical algorithm is second-order accurate in space discretization and time integration. The scheme is stable for a Courant number $\leq 2$. Local time steps are used to accelerate to a steady-state solution by setting the time step at each point to the maximum value allowed by the local Courant-Friedrichs-Lewy (CFL) condition. For the present work, the calculations performed are double precision and of second-order accuracy in both space and time.

\section{Initial and boundary conditions}

The freestream conditions for each trajectory point are tabulated in Table 1, which are used as initial conditions. The transonic and supersonic wind tunnel [13] at Institute of Space and Astronautical Science (ISAS) is of a blow down type. The Reynolds number based on the model diameter $\mathrm{D}$ is $6.7 \times 10^{5} \approx 1.5 \times 10^{6}$. The freestream flow values are used to initialize the whole flowfield. The freestream flow values are used to initialize the whole flowfield.

Table-1: Test conditions

\begin{tabular}{|l|l|l|}
\hline $\mathbf{M}_{\infty}$ & $\mathbf{q}_{\infty} \times \mathbf{1 0}^{\mathbf{5}} \mathbf{P a}$ & $\mathbf{R e}$ \\
\hline 1.2 & 0.630 & $1.64 \times 10^{6}$ \\
\hline 2.0 & 0.819 & $2.20 \times 10^{6}$ \\
\hline 3.0 & 0.792 & $2.70 \times 10^{6}$ \\
\hline
\end{tabular}

The boundary conditions are as follows: a noslip condition and isothermal wall is considered as a solid wall boundary condition. At the inflow, all the flow variables are taken at the freestream values as tabulated in Table 1. A symmetry condition is imposed on the centre line upstream and downstream of the reentry capsule. All variables are extrapolated at the outer computational boundary. The computational code is based on the author's in house code, which has been applied for many compressible flowfield including transonic and supersonic flows.

\section{Geometry of the MUSES-C}

The baseline geometry of the MUSES-C sample return capsule is shown in Fig. 2(a) and consists of a $45^{\circ}$ half angle cone, spherically blunted cone forebody of a $45^{\circ}$ half angle conical after body. The nose radius $\mathrm{R}$ is $202 \mathrm{~mm}$ and overall diameter D is 404 $\mathrm{mm}$. The afterbody base has a diameter $234 \mathrm{~mm}$. the $\mathrm{cg}$ of the baseline configuration is $120 \mathrm{~mm}$ aft of the nose. The length of the capsule is $202 \mathrm{~mm}$. The shape and dimensions of MUSES-C sample return capsule are mentioned in Ref. [13].

\section{Computational grid}

One of the important factors that influence the numerical simulation is the proper selection of the grid arrangement and size. The body-oriented grids are generated using a homotopy scheme [18]. The stretched grids are generated in an orderly manner. We discretize the shroud by 64 (non-uniform and non-overlapping) grid points for the cylindrical polar coordinate system. 20 grid points defining the fore body were exponentially stretched for adequate resolution of boundary layer. The origin of the $\mathrm{x}-\mathrm{r}$ plane is at the stagnation point with the positive $\mathrm{x}$-direction along the capsule. A mono-block with sub-domain [18] having exponentially stretched in normal direction structured 
and non-overlapping grids have been employed to accurate resolve the front and base flow regions.

The grid-stretching factor is selected as 5, and the outer boundary of the computational domain is maintained as $1.5-2.5$ times maximum diameter $\mathrm{D}$ of the reentry module. In the downstream direction, the computational boundary is about $6-9$ times the diameter of the space module; D. A typical grid over the MUSES-C space return capsule is shown in Figure 2(b) where the body contour and the outer computational domain are depicted. The grid has been generated with appropriate clustering of mesh points to accounting resolve boundary layer and shear layer. The grid arrangement is found to yield a relative difference of about $\pm 5 \%$ in the computation of fore-body aerodynamic drag coefficient. The convergence criterion is based on the difference in density values at any of the grid points, between two successive iterations $\left|\rho^{\mathrm{n}+1}-\rho^{\mathrm{n}}\right| \leq 10^{-5}$ where $\mathrm{n}$ is time-step counter. The present numerical algorithm is described in detail in Ref. [8] and validated with many test cases.
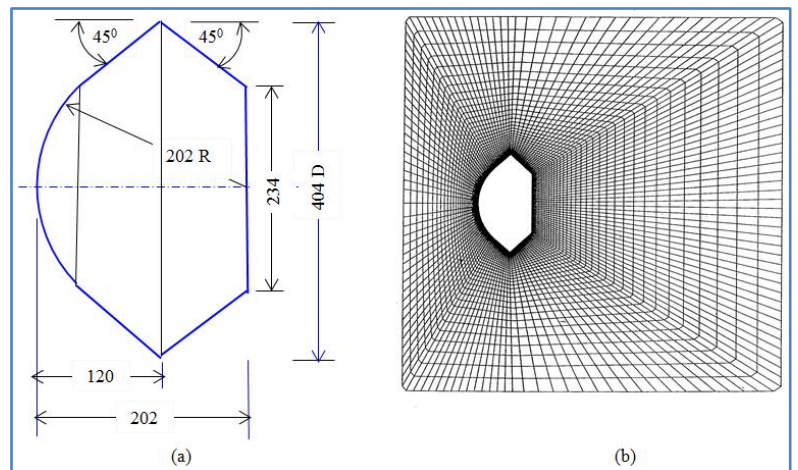

Fig-2: (a) Geometry and (b) computational grid over the MUSES-C space return capsule

\section{RESULTS AND DISCUSSION}

\section{A. Flowfield characteristics}

Figure 3 shows a close-up view of velocity vector plots for $\mathrm{M}_{\infty}=1.2-3.0$. The supersonic outside flow is separated from the relatively low velocity core of the base-flow region by a separated shear layer, and this shear layer has an initial thickness and structure that are due to the body boundary layer. A dividing streamline originates at the separation point and is the inner boundary of the flow originating upstream as illustrated in Fig. 1(a). A stagnating streamline separates the flow that continues downstream through the neck from that which turns back and recirculates. Emanating flow from separation region is the dividing stream surface, which defines the boundary of the recirculation region. The flowfield outside the dividing streamline proceeds from the separation point in a viscous mixing layer that converges to a single flow stream at the wake neck. It is important to say that all the essential flow characteristics are well captured by present flow solver.

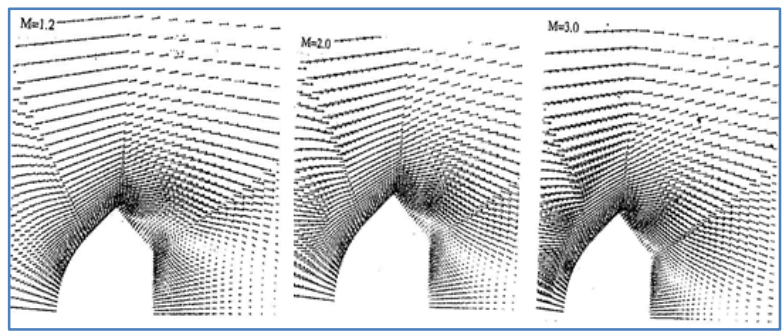

Fig-3: Close-up view of velocity vector plots

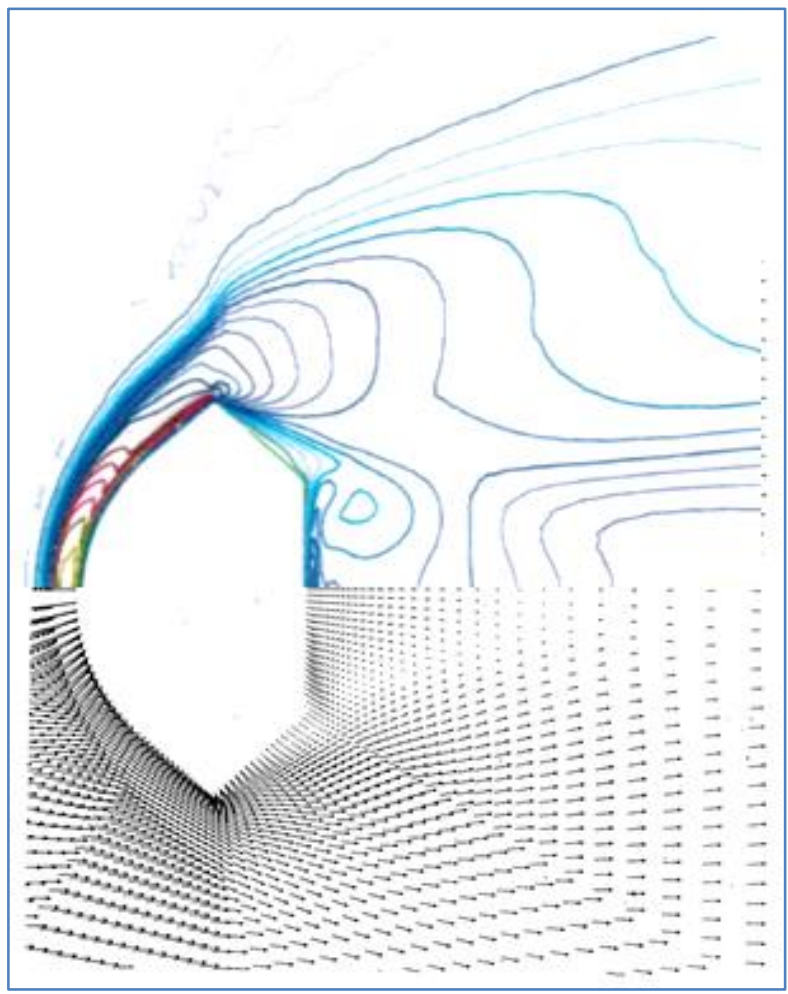

Fig-4: Zoomed view of velocity vector plot with streamlines $\mathrm{M}_{\infty}=\mathbf{3 . 0}$

Figure 4 depicts zoomed view of velocity vector plot with streamlines $\mathbf{M}_{\infty}=3.0$. In the fore-body region, the fluid strongly decelerated through the bow shock wave. At the shoulder, the flow turns and expands rapidly, and boundary layer detached and forming a free shear layer that separates the inner recirculation region behind the base from the outer flow field. Figure 5 shows enlarge view of contour plots with streamlines at $\mathbf{M}_{\infty}=3.0$. From the near wake neck streamlines and vorticity distributions we observe a substantial change in the structure of the recirculation wake with the Mach number. The comparison between the velocity vector with the stream lines, and contour plots is to reveal the identical flow behavior that also show the accuracy of the flow solver. 


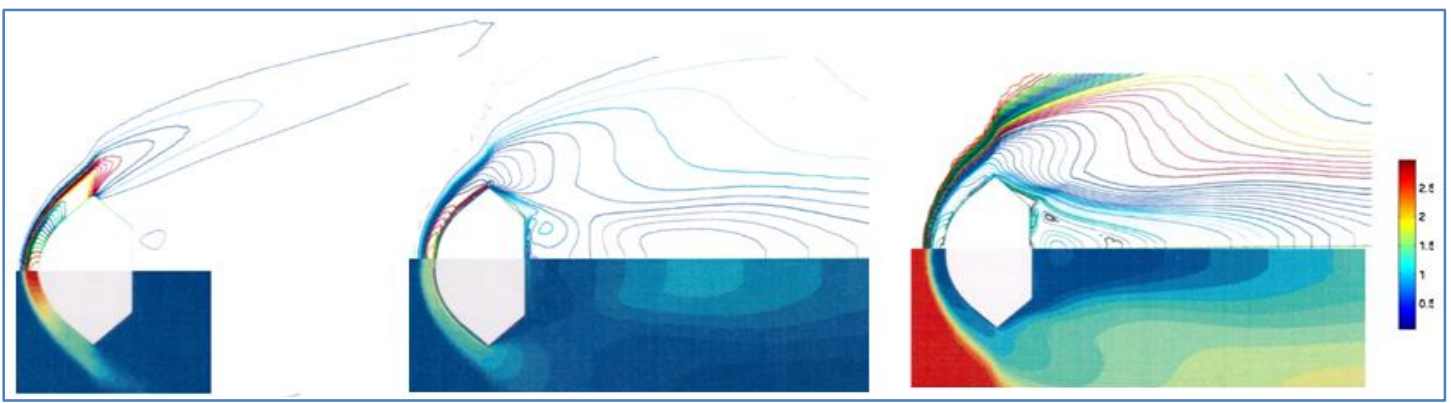

Fig-5: Enlarge view of pressure contours with streamlines at $M_{\infty}=3.0$

Figure 6 shows a close-up view of the pressure, Mach and temperature contours in the symmetry plane around the MUSES-C space capsule for freestream Mach numbers 1.2 - 3.0 at zero angle of attack. The base flow features observed from the shadowgraph [13] are very similar to one another and includes several known wake features: shear layer, neck region and recompression shocks. It can be visualized from the vector plots that all the significant flowfield features such as a bow shock wave, rapid expansion fans at the shoulder, recirculation region with a converging free-shear layer and formation of the vortex flow in the base-shell region are well captured for various freestream Mach numbers. The wake flowfield immediately behind the space vehicle base exhibits complex flow characteristics. The formation of the bow shock wave on the fore-body is depends the freestream Mach numbers $\mathbf{M}_{\infty}$. The bow shock wave moves close to the fore-body with the increasing freestream Mach numbers $\mathbf{M}_{\infty}$ and the stand-off distance between the bow shock wave and the fore body decreases with the increasing $\mathbf{M}_{\infty}$. The wake flowfield, immediately behind the capsule base, exhibits complex flow characteristics as observed in the vector plots. The flow around the space reentry capsule is divided into two regions; namely, inside and outside of the recirculation zone, and the shear layer separating the regions. The flowfield is very complex because of the back-shell. First called by the lip shock and further downstream by recompression shock. At the end of recirculating flow past the neck, the shear layers develop in the wake trail.
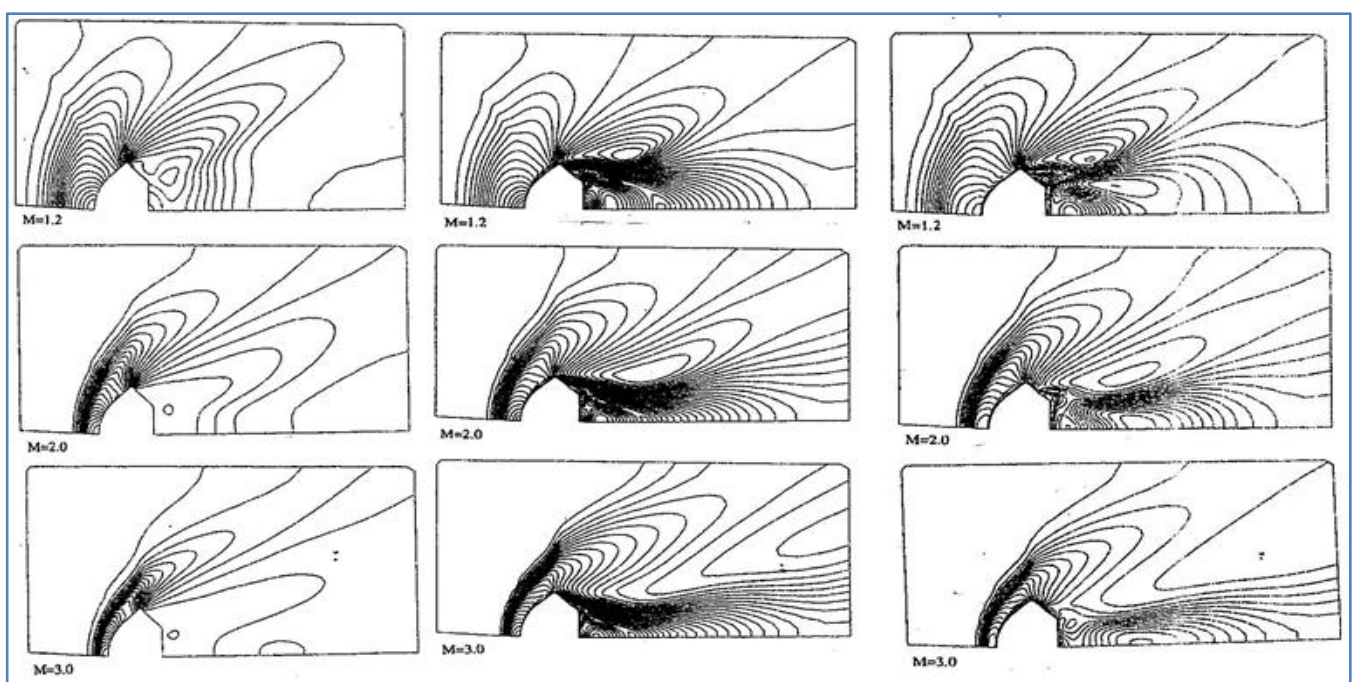

Fig-6: Pressure, Mach and temperature contours over the MUSES-C capsule

\section{B. Surface pressure coefficient over the capsule}

The using the computed surface pressure over the MUSES-C, the surface pressure coefficient can be calculated using following expression

$$
C_{P}=\frac{\left(1-\frac{p}{p_{\infty}}\right)}{\frac{1}{2} \gamma M_{\infty}^{2}}
$$

where $\mathrm{p}_{\infty}$ is the freestream pressure. Figure 7 depicts the variation of surface pressure coefficient $\mathrm{Cp}$ over the surface of the MUSES-C space return capsule at freestream Mach numbers of $\mathrm{M}_{\infty}=1.2-3.0$. The $\mathrm{x}=0$ is the location of the stagnation point. The $\mathrm{Cp}$ variations are gradually decreasing over the spherical cap and remain nearly constant in the conical section as depicted in Figure 7. A sudden fall in $\mathrm{Cp}$ is seen on the shoulder of the MUSES-C.

\section{Fore-body aerodynamic drag coefficient}

The aerodynamic drag is influenced by the fore-body shape. The fore-body aerodynamic drag 
coefficient for various reentry configurations at high speeds can be computed using following expression:

$$
\left(C_{D}\right)_{F}=\frac{2 \pi \int_{i}\left(C_{P}\right)_{F} r_{i} \sin \psi d x}{A_{\max }}
$$

where $\mathrm{r}$ and $\psi$ are local radius and local inclination angle in the $\mathrm{x}$-direction station $\mathrm{i}$ respectively. $\mathrm{A}_{\max }(=$ $0.25 \pi \mathrm{D}^{2}$ ) is the maximum cross-sectional area of the reentry module. Table 2 shows comparison between numerically computed axial force $\left(\mathrm{C}_{\mathrm{D}}\right)_{\mathrm{F}, \mathrm{C}}$ with the measured $\left(\mathrm{C}_{\mathrm{D}}\right)_{\mathrm{F}, \mathrm{M}}$ of wind-tunnel test [13]. The comparison shows good agreement between them.

Table-2: Aerodynamic axial force coefficient

\begin{tabular}{|c|c|c|c|}
\hline \multirow{2}{*}{$\begin{array}{l}\text { Mach } \\
\text { number }\end{array}$} & \multicolumn{2}{|c|}{$\left(C_{D}\right)_{F}$} & \multirow{2}{*}{$\begin{array}{l}\text { Percentage difference } \\
{\left[\left(\mathbf{C}_{\mathrm{D}}\right)_{\mathrm{F}, \mathrm{M}}-\left(\mathbf{C}_{\mathrm{D}}\right)_{\mathrm{F}, \mathrm{C}}\right] /\left(\mathbf{C}_{\mathrm{D}}\right)_{\mathrm{F}, \mathrm{M}}}\end{array}$} \\
\hline & Measured, $\left(C_{D}\right)_{F, M}$ & $\begin{array}{l}\text { Computed, } \\
\left(C_{D}\right)_{F, C}\end{array}$ & \\
\hline 1.2 & 1.33 & 1.316 & 1.052 \\
\hline 2.0 & 1.26 & 1.210 & 3.968 \\
\hline 3.0 & 1.18 & 1.102 & 6.610 \\
\hline 5.0 & 1.12 & 1.073 & 4.196 \\
\hline
\end{tabular}

\section{Base pressure coefficient}

Characteristics of flow features around the blunt body at supersonic speeds are described in the above section. The high surface pressure on the fore-body results in the high aerodynamic drag and low pressure on the base which is required for the aero-braking application. The base pressure coefficient can be calculated using following expression

$$
\left(C_{P}\right)_{B}=\frac{\left(1-\frac{p_{B}}{p_{\infty}}\right)}{\frac{1}{2} \gamma M_{\infty}^{2}}
$$

Where subscript B represents the base stagnation point. The base pressure coefficient $\mathrm{Cp}$ along the base centre point to the corner tip of the capsule in the radial direction is shown in Figure 8 for the MUSES-C space vehicle. For the freestream Mach number $1.2-3.0$. The $\mathrm{Cp}$ is high on the corner due to presence of the expansion fan. The base pressure coefficient $\mathrm{Cp}$ remains near to a constant value on the base plane. It is important to mention here that the base pressure coefficient $\mathrm{Cp}$ variation is gradual attributed to beveled shape shoulder of the MUSES-C. Thus, the base pressure coefficient exhibits the influence of the freestream Mach number. In the base region, the base pressure coefficient is decreasing with increasing $\mathbf{M}_{\infty}$.

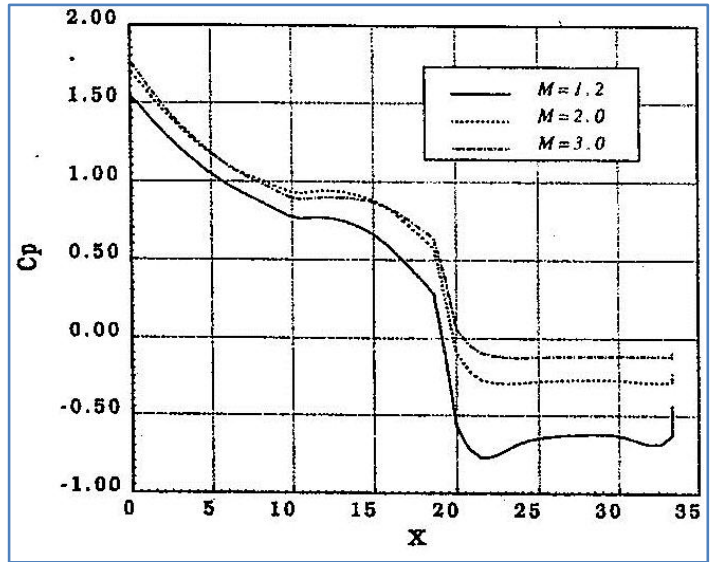

Fig-7: Axial variation of surface pressure over the MUSES-C

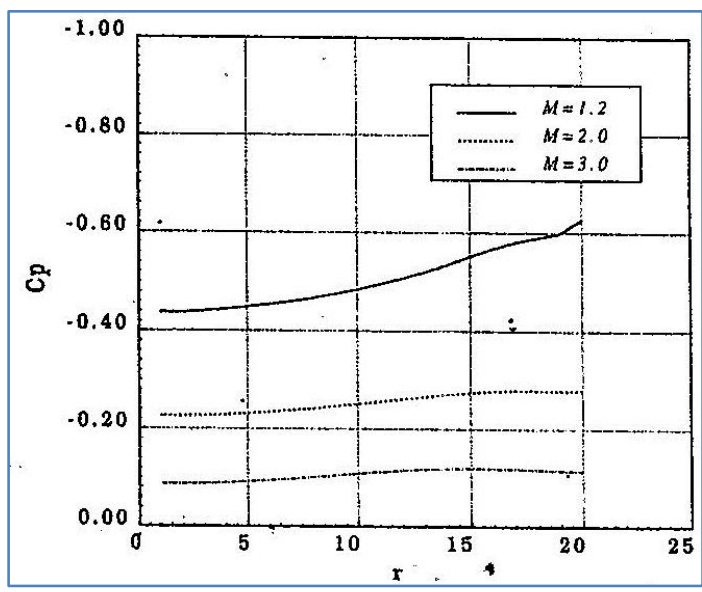

Fig-8: Base pressure on the MUSES-C

The base pressure can be calculated as

$$
\left(C_{P}\right)_{B S}=\frac{\left(p_{B S}-p_{\infty}\right)}{\frac{1}{2} \rho_{\infty} V_{\infty}^{2}}
$$

The $\mathrm{C}_{\mathrm{PBS}}$ base pressure coefficient compares well with the numerical results for freestream Mach numbers $\mathrm{M}_{\infty}=1.2-5.0$. The base pressure coefficient can be computed conveniently knowing the trajectory conditions of the space capsule and corresponding discharge coefficient $C_{d}$. The value of maximum crosssection area of the capsule which is geometrical parameters of the capsule and $\mathrm{V}_{\mathrm{C}}$ is the space volume created to fill-up depends on the freestream Mach number and area of the base at the maximum diameter of the capsule.

\section{CONCLUSION}

The steady-state, ideal gas, laminar CFD computations are performed on a two-dimensional axisymmetric model of the external shape of the MUSES-C. A structured two-dimensional mesh is used in this study. A main aim of the paper is to analyze numerically the base pressure over the MUSES-C space reentry vehicle at freestream Mach number range of 1.2 
- 3.0. A numerical algorithm is described to solve compressible laminar axisymmetric Navier-Stokes equations over various reentry capsules. The CFD method yields flowfields over space vehicles without the interference of the sting-model attachment in wind tunnel experiments. A low pressure is formed in the base region of the capsule which is characterized by a low-speed recirculation region. The approaching boundary layer separates at the corner and the freeshear layer is formed in the wake region. The base pressure coefficient decreases as Mach number increases. The wake flow also shows a vortex attached to the corner with a large recirculation, which depends on the freestream Mach numbers.

\section{REFERENCES}

1. Cassanto JM. A base pressure experiment for determining the atmospheric pressure profile of planets, Journal of Spacecraft and Rockets.1973;10(4): 253-261.

2. Tanner M. Steady base flows, Progress in Aerospace Sciences. 1984; 21(2): 81-157.

3. Tanner M. Base pressure in supersonic flow: Further thoughts about theory, AIAA Journal. 1992; 30(2): 565-566.

4. Lamb JP and Oberkamf WL. Review and development of base pressure and base heating correlations in Supersonic flow, Journal of Spacecraft and Rockets.1993; 32(1): 8-23.

5. Baum E, King HH and Denison MR. Recent studies of the laminar base-flow region, AIAA Journal.1964; 2(9): 1527-1534.

6. Grasso F and Pettinelli C. Analysis of laminar nearwake hypersonic flows, Journal of Spacecraft and Rockets. 1995; 32(6): 970-980.

7. Berger SA. Laminar Wakes, First edition, American Elsevier, New York; 1971.

8. Mehta RC. Numerical Simulation of Base Pressure and Drag of Space Reentry Capsules at High Speed, in the Hypersonic Vehicles Past, Present and Future Developments, Eds: G. Pezzela and A. Viviani, IntechOpen, London, UK. 2019: 115-135.
9. Gnoffo PA, Weilmuenster KJ, Braun RD and Cruz CL. Influence of sonic-line location on Mars pathfinder probe aerothermodynamics, Journal of Spacecraft and Rockets. 1966;33(2):169-177.

10. Instani V. Reentry capsule for sample return from asteroid in the planetary exploration mission, $5^{\text {th }}$ International Seminar of Aerospace Science and Technology, Journal of Physics, Conference series. 2018; 1005-02049.

11. Abe T, Sato SI, Matsukawa Y, Yamamoto K, Hiraoka K. Study for dynamically unstable motion of reentry capsule. In34th Thermophysics Conference 2000 (p. 2589).

12. Inatani $\mathrm{Y}$, Ishii $\mathrm{N}$. Design overview of an asteroid sample return capsule. ISAS Report SP. 2003 Mar; $17: 1-5$

13. Hiraki K, Inatani Y. The aerodynamic data base for asteroid sample return capsule. ISAS Report SP. 2003 Mar; 17:345-63.

14. Ishii N, Yamada T, Hiraki K, Inatani Y. Reentry motion and aerodynamics of the muses-c sample return capsule. Transactions of the Japan Society for Aeronautical and Space Sciences. 2008;51(172):65-70.

15. Fujita K, Takayanagi H, Matsuyama S, Nishimura S, Yamada K, Abe T. Experimental and Numerical Assessment of Aerothermal Environments About Jupiter Trojan Sample Return Capsule. In30th International Symposium on Shock Waves 22017 (pp. 839-843). Springer, Cham.

16. Desikan SL, Patil MM, Subramanian S. Understanding of flow features over a typical crew module at Mach 4. The Aeronautical Journal. 2015 Jun;119(1216):727-46.

17. Jameson A, Schmidt W, Turkel E. Numerical solution of the Euler equations by finite volume methods using Runge Kutta time stepping schemes. In14th fluid and plasma dynamics conference 1981 Jun 23 (p. 1259).

18. Mehta RC. Multi-Block Structured Grid Generation for Computational Fluid Dynamics, Scholar Journal of Engineering and Technology. 2017;5(8): 387-219. 